\title{
Assessment of the intellectual capital evaluation practices in Romanian IT companies
}

\author{
Cynthia Bianka INCZE \\ The Bucharest University of Economic Studies, Bucharest, Romania \\ incze_cynthia@yahoo.com \\ Simona VASILACHE \\ The Bucharest University of Economic Studies, Bucharest, Romania \\ simona.vasilache@gmail.com
}

\begin{abstract}
Intellectual capital started to raise and become a focal point of many businesses as they started invest in their own knowledge based activities and recognize its importance. In today's world can be observed a more dynamic, flexible and growth oriented business environment than ever. Thus, the need for an increased amount of intangible assets in businesses lead to the recognition of the intellectual capital as a competitive advantage and strategic asset. Due to its expanding importance and relevance a significant number of measurement, valuation and evaluation methods were developed. Consensus regarding different methods was not yet reached, but all these methods are designed to help to get an approximation of the reality, thus contributing in short-term and long-term decision making. The aim of the paper is to assess the level of intellectual capital evaluation practices in multinational IT companies and IT SMEs in Romania. The study is questionnaire based and represents a mix of quantitative and qualitative research. Overall, although the challenge of intellectual capital evaluation remains significant, this study leads to the opportunity to identify evaluation patterns, best practices and a short list of useful evaluation indicators for businesses which already are or could be implemented in the near future.
\end{abstract}

Keywords: Intellectual capital, SME, multinational company, evaluation methods.

\section{Introduction}

In the $21^{\text {st }}$ century many organizations consider intellectual capital a priority in their agenda (Marr and Schiuma, 2004). Intellectual capital is linked to strong concepts such as innovation, brand value, customer loyalty and commitment, thus no wonder that researchers concentrate their work in this field. Also, the need for constant growth and the dynamicity of the economic world boosted the interest in intellectual capital.

Intellectual capital was recognized as strategic asset and competitive advantage. Due to its importance, a significant number of measurement and evaluation methods were developed mainly in the Nordic developed countries.

In addition, intellectual capital is part of the knowledge economy, which is today's most valuable resource of value creation and its importance is once again highlighted the European Union level through the Lisbon aim of having the EU becoming the most competitive knowledge-based economy in the world.

Academics together with policy-makers found a causal relationship between innovation and research \& development investments, however, it is considered too simplistic to measure just R\&D investments and broader view and exploration is needed including intellectual capital research. 
In fact, as Lev (2014) stated, intellectual capital researches are too narrowly focused on the question of reporting and disclosure, since intellectual property - such as intangible assets are measured and are highly regulated in the financial world being present on the balance sheet, many businesses realized that an extensive number of intangible elements cannot be identified on the financial statements, that are highly valuable and their proper management can lead to their further growth. Such element is for example the brand image or customer loyalty. The fact to measure something which in its own seems unmeasurable may seem a paradox, but a careful look from different angles could lead us to the development of new intellectual capital measurement and management practices so that the final outcome would be an enhanced and targeted business growth. In a series of research papers, Bratianu and his co-authors suggested not to stop at measuring intellectual capital just for the sake of accounting and reporting, but to move away and start finding the essence of intellectual capital in rational, emotional and spiritual knowledge (Bratianu, 2018; Bratianu and Bejinaru, 2017; Bratianu et al., 2011; Bratianu and Orzea, 2013).

The concept of intellectual capital was so debatable in last two decades that unfortunately up to this moment no consensus was reached over the measurement and evaluation methods and financial reporting (Guthrie et al., 2012) due to its complexity and dynamicity (Montemari et al., 2013). At this point, intellectual capital cannot be hundred percent accurately measured, however, the existence of different models and approaches can present an estimation of the reality and also leaves open the opportunity to find further connections and synergies, so that in time the evaluation of intellectual capital of an organization will be reliable, accurate and comparable to other organizations.

Intellectual capital most widely comprises three categories human, relational and structural capital. Most of the evaluation methods that used for categorizing and measuring intellectual capitals ignored the dependencies between subcomponents. The aim of this study is to evaluate and prioritize the intellectual capital subcomponents by taking into consideration their dependencies.

\section{Literature review}

Intellectual capital was defined by many scholars, some of the most notable definitions are "the hidden wealth" (Andriessen, 2003, p.3) and "packaged useful knowledge" (Stewart, 1997, p.7). Also, Stewart (1997, p. 221) concluded "Intellectual capital has been considered by many, defined by some, understood by a select few, and formally valued by no one". Brooking defined it as the difference between one's book value and market value, pointing out that this difference in value cannot be found on the balance sheet.

Intellectual capital represents the resources and capabilities that enhance creativity, inventiveness and new fresh ideas (Andriessen, 2001). Shortly said, intellectual capital is an intangible knowledge based resource which role is value creation.

According to Suciu (2004) knowledge economy is characterized by instability and chaos mainly due to the accelerated technological progress and globalization. Knowledge economy is complex and dynamic drawing attention of the increasing number of factors that must be taken in consideration like e-commerce, multi-functional teams etc. (Suciu, 2004).

Resources that are rare, and impossible to copy or replace and valuable for the society are the source of long-lasting competitive advantage (Kozak, 2011). 
Stewart (1997) suggested, that when considering to develop a new intellectual capital evaluation tool or model keep in mind to use common sense and simplicity, focusing on just what is strategically essential and develops intellectual wealth and growth.

Also, Kaplan and Norton (2001) argued that is insufficient to measure past events, it is important to focus on the future.

Intellectual capital most widely comprises three categories human-, relational- and structural capital. Human capital is represented by the organization's employees comprising their skills, talents, knowledge and experience which is deployed in their day to day activity at work. This knowledge can be tacit and explicit knowledge. Also, some of this human knowledge can be unique at individual level, such as motivation, flexibility, innovation capacity etc.

Further, relational capital represents the relationship with customers, suppliers and other stakeholders. It mainly focuses on how to nurture these relationships and make it trustfully and growing for both sides (company - customer, company - supplier, etc.). Last but not least, structural capital is the amount of knowledge that was developed and remains in the organization, such as procedures, routines, systems etc. Out of the categories of intellectual capital, structural capital is the one which is mostly legally protected, becoming a property right.

The subcategories of intellectual capital of Nedjati and Izbirak (2013) can be find bellow in Figure 1. Subcategories help to understand and tackle intellectual capital at a more specific level.

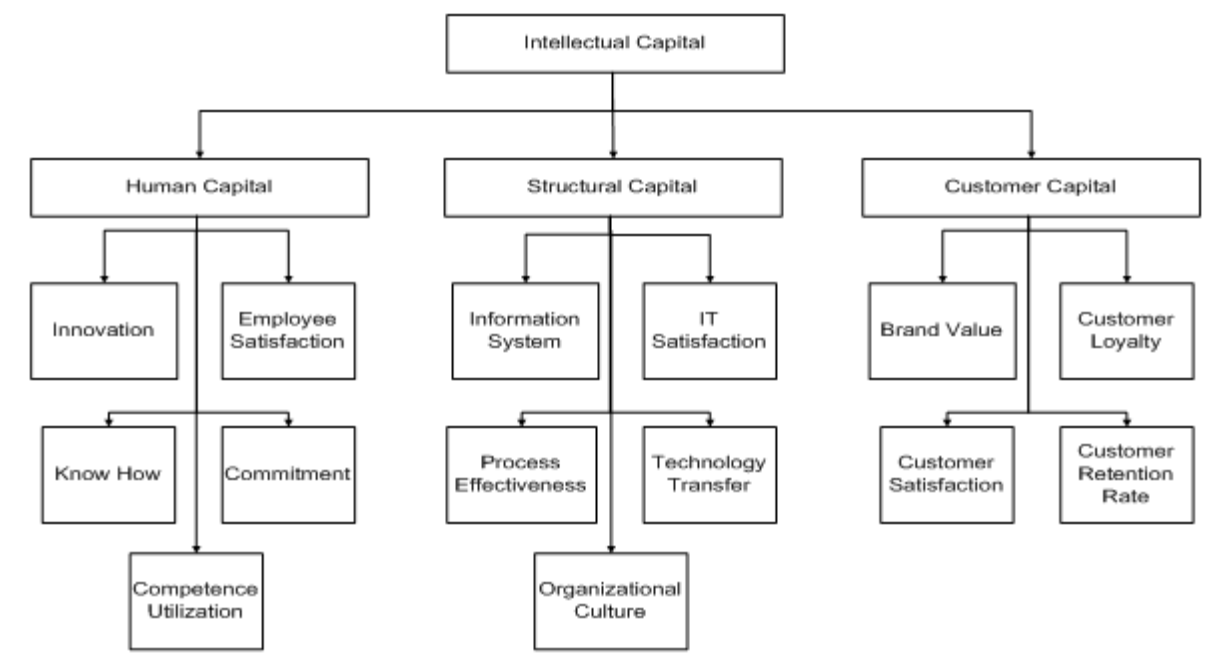

Figure 1. Intellectual capital subcomponents

Source: Nedjati et al., 2013, p.139

Measurement methods of intellectual capital were summarized by Sveiby (2007). The four main approaches in measuring intangible assets are market capitalization methods (MCM), return on asset (ROA), direct intellectual capital methods (DIC) and scorecard methods (SC). Table 1. presents the first two methods mostly use information obtained from the market, from organization's annual reports, while the other two methods require information within the company so they are called management models. 
Table 1. Measurement methods according to Sveiby (2007)

\begin{tabular}{|l|l|}
\hline Method & Type of model \\
\hline Market capitalization method (MCM) & Market model \\
\hline Return on asset (ROA) & Market model \\
\hline Direct intellectual capital methods (DIC) & Management model \\
\hline Scorecard method (SC) & Management model \\
\hline
\end{tabular}

Since for these four methods there are many models developed, for illustration purposes we will present the one that is mostly notable and used in its category according to researches.

\section{Market capitalization method}

The Q ratio was introduced by Tobin (1969) and initially was not intended for intellectual capital measurement, but it proved to be useful since it measures the market to book value ratio. Tobin said that the combined market value of the company should be equal with their replacement cost (Equation 1.). A higher $Q$ indicates that the company is earning more on a class of assets.

$$
\text { Q Ratio }=\frac{\text { Total Market Value of Firm }}{\text { Total Asset Val ue }}
$$

Equation 1. Tobin's Q ratio (1969)

Source: Tobin, 1969

Steward (1997) completed that it is possible to achieve a higher $Q$ by having unique assets and those bringing higher profits. However, Bouteiller (2000) draw the attention that the $Q$ ratio can be used in benchmarking comparisons in similar industries in which the company activates and by having similar types of assets. Although, the formula is relatively easy to be applied, it is difficult to estimate the replacement costs of a company assets especially if there is no market for such asset. Also, the majority of researchers believe that the $Q$ ratio is an effective performance measurement tool, however does not measure strictly the intellectual capital.

\section{Return on assets}

ROA method - attempts to measure the efficiency or potential value of IC. ROA methods are Value added intellectual capital coefficient (VAIC), Economic value added and Knowledge capital earnings. Value added intellectual capital coefficient (VAIC). The method was developed by Pulic (2004) and it determines the size of the IC and its efficiency. Data for VAIC calculation is obtained from audited financial reports, thus it is reliable and verifiable and is suitable for statistical analysis. Also, VAIC breaks down IC into structural and human capital. However, the drawback is that VAIC method can be firm specific and not easily comparable.

\section{Direct intellectual capital methods}

These methods need data from inside the company and according to Sveiby (2007) for each intangible asset and IC component monetary value is assigned. 
DIC methods are Citation weighted patents, Financial method of intangible asset, Inclusive valuation methodology, Total value creation, Human resource costing, The value explorer, Technology broker and Intellectual asset valuation.

Technology broker method received its name from the Technology Broker consulting company. Brooking (1996, p.12) claimed that IC is "the combined intangible assets which enables the company to function". Brooking identified 4 categories for IC: intellectual property assets, market assets, human-centered assets and infrastructure assets. Intellectual property assets are patents, trademarks, copyrights, etc. Market assets represent all assets which establish a good relationship between customers and the company, like distribution channels, brands, reputation etc. Human centered assets include employee expertise, capabilities and skills, through which employees achieve their full potential. Finally, infrastructure assets referring to technologies, managerial structures and systems. For the 4 categories identified monetary value can be assigned using either the cost-, income- or market approach. In the cost approach, the value constitutes the replacement cost; in case of market approach, the value is established by the relevant market and in the income approach, the monetary value of an asset is the income producing potential of the asset. In case of cost approach and market approach, the replacement cost respectively the relevant market could be unknown. Also, in case of income approach, the determination of the income producing potential is highly subjective. The conversion of the qualitative results of the four IC categories into monetary units is fuzzy and criticized.

\section{Scorecard methods}

This method focuses on identifying the individual component of intellectual capital through graphical representation often in form of a scorecard or chart in order to ensure continuous managerial improvement and value creation. Unlike the previous methods, there is no monetary value estimated and linked to the scorecard measuring methods. Scorecard methods are Balanced scorecard, Skandia navigator, National intellectual capital index, value chain scorecard, Intangible asset monitor, Value creation index, IC index, IC rating, Holistic accounts and Danish guidelines.

Skandia Navigator model was developed by Edvinsson and Malone (1997) and contains a set of key indicators that provide an overall view on company performance and goal achievement. According to the model, the total market value of the company equals it's total financial capital and total intellectual capital. Below, in Figure 2 can be seen that IC is divided into human capital and structural capital. Structural capital is further divided in customer and organizational capital, while organizational capital comprises innovation capital and process capital. 


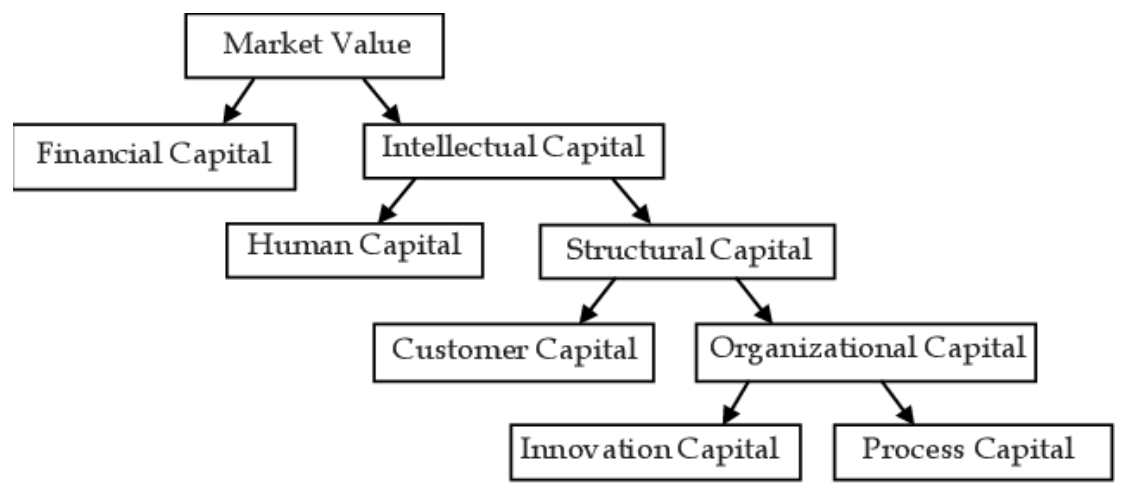

PICBE $\mid 875$

Figure 2. Skandia Navigator Scheme (1997)

Source: Edvinsson and Malone, 1997

The model contains 164 indicators covering all focus areas presented in Figure 3. The financial focus represents the financial statements relating to past events, presenting the company financial situation at a certain time in the past. Further, the customer and process focus are the main to pillars ensuring external and internal well-functioning. Through customer focus the actual value of the two-way relationship can be measured, while through process focus with enhanced technology and support overall value creation is achieved for the organization and customers.

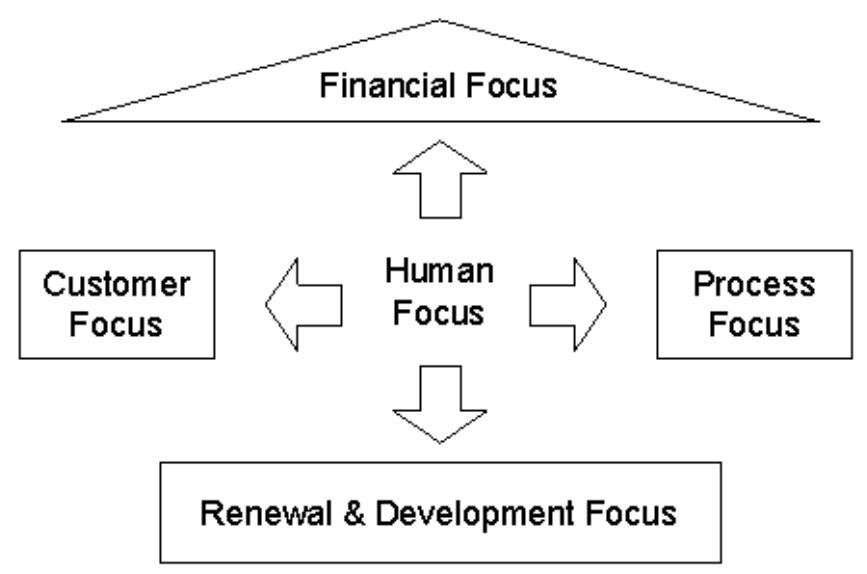

Figure 3. Skandia Navigator management model

Source: Edvinsson and Malone, 1997

The renewal and development focus embeds the innovation, R\&D of new products, different trainings and strategic actions which are needed in the continuous development process of the companies. Finally, the center of the model is represented by the human focus, which needs to properly communicate with the other four focuses and act like a bridge between them. The human focus is extremely important as according to Edvinsson and Malone without a strong and successful human capacity none of other value creating activities would exist. The Skandia Navigator is the mostly researched, used and cited model in the IC domain.

It was recognized that intellectual capital management oversteps knowledge management by the simple fact that the human capital is leveraged together with the 
structural capital and due to interaction through relational capital value is born (Edvinsson, 1997).

\section{Methodology}

The aim of the paper is to assess the level of intellectual capital evaluation practices in IT multinational companies and SMEs in Romania, whether there is any method of keeping PICBE | 876 track of intellectual capital in Romanian enterprises.

The study fits the descriptive research design, thus both quantitative and qualitative research methodology can be applied. The descriptive research design fits the best, since it is a hand on approach to identify tendencies and correlations in the intellectual capital field.

For the study purpose an online questionnaire was used and distributed to IT multinational companies and IT small and medium enterprises present in Romania. The questionnaire contained 15 questions predominantly multiple choice or closed questions, but with the possibility of adding own answers. Primary data was gathered which was cleared by inconsistent data.

The study can be further developed by conducting a focus group, deep interviews or mini case studies. These are mostly qualitative researches, which might enhance the current qualitative researches about intellectual capital.

\section{Results and discussions}

For the questionnaire, we managed to collect 113 answers, out of which 76 answers from multinational companies and 37 answers from small and medium enterprises. The type of the enterprise was decided based on the number of employees (small - up to 49 employees, medium - up to 249 employees, large - over 250 employees) and their presence in other foreign countries.

In case of SMEs we found that there is no official intellectual capital evaluation on a regular basis or the employees are not aware of them. In case of multinational companies a high percent of respondents, 58\% do not know, if intellectual capital is evaluated on a regular basis, while $24 \%$ firmly confirmed that intellectual capital is not measured and the remaining $18 \%$ claimed having intellectual capital evaluations regularly.

In order to find out more about these IT companies, we were interested in the 3 most important key drivers or corporate value, as is called nowadays. Respondents were able to choose between innovation, customer relations, management skills and capabilities (accountability and empowerment), alliances, brand value, employee attraction and retention and environmental and community issues.

In case of SMEs, the most popular answers were innovation, customer relations and employee attraction and relations, while in case of multinational companies the most important key drivers were innovation, management skills and capabilities and brand value. SMEs have a stronger sense for developing customer relations, since they rely more on acquiring new customers, while in case of multinational companies, although customer relations are not neglected at all, however, the existence of a well sustained marketing and brand image speaks for itself.

We saw that traditionally intellectual capital is categorized as human-, relational- and structural capital. In this study, we were interested to see which aspects are measured in each subcategory of intellectual capital, thus we prepared some options for the respondents 
to be easier to recognize and thick but leaving them also the option to give their input, if there are other options we did not consider. For each category, we considered seven evaluable and measurable aspects. Thus, for the better view of the 21 answer possibilities we created an intellectual capital footprint for IT SMEs and separately for multinational companies.

Below in Figure 4. is presented the footprint of the intellectual capital in multinational companies.

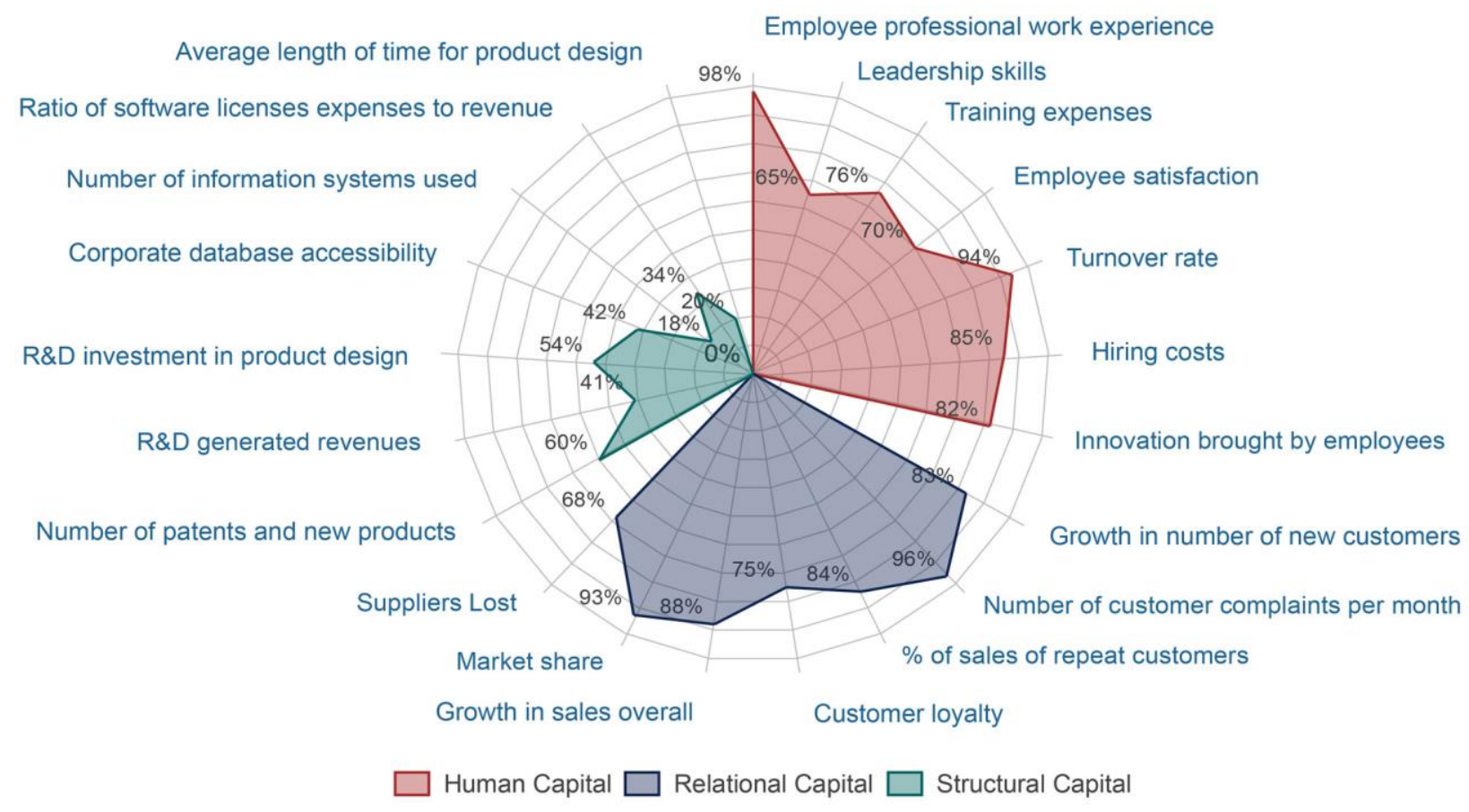

Figure 4. Intellectual capital evaluation indicators footprint in IT multinational companies in Romania

Source: Authors' own research and presentation

Human capital and relational capital evaluation is promising and quite high, since over $50 \%$ of the respondents recognized many of these key performance indicators in their organizations that are linked with intellectual capital. In case of human capital $98 \%$ of the respondents choose employee professional work experience as being measured, which is no wonder since, IT employees must perform ability tests when employed and also after different trainings, thus their experience, technical knowledge level is tested. Turnover rate, hiring and training costs are also measured usually by the HR department. Interestingly, innovation brought by employees scored high, which means that employees in the IT field are encouraged to innovate and they are motivated to bring more and more innovation. Looking at relational capital the percentages it can be seen that there is a great focus on the relationship with different stakeholders. In case of structural capital less respondents recognized the indicators in their organizations. However, the number of new patents indicators still scored $60 \%$ while R\&D investments were also important being recognized by $54 \%$ of the respondents. 
The lowest percentage scored was related to the number of information systems used. Probably this information is not so relevant even if it's measurement is simple. Overall, it can be seen that in case of human and relational capital multinational companies take many of the proposed measurement and evaluation indicators, however, there is still room for improvement in case of the structural capital evaluation.

Moving forward and performing the same analysis on the SMEs we can see some differences at individual indicator level, such as leadership skills are lower, than in case of multinational companies. This can be explained by the fact that in small and medium companies the hierarchy is flat and accountability of each individual of their job is much important than leadership skills. Although, leadership is important sometimes in case of SMEs it requires more to have a hands-on approached and involved manager (FSB, 2016). Another difference is regarded the importance of measurement of hiring costs and training expenses, small companies are highly impacted and sometimes they cannot cope with the benefits provided by multinational companies. However, small and medium companies focus on being different and outstanding from the market, thus employee professional satisfaction is high. In case of SMEs, the relationship with stakeholders is crucial especially with customers. The fact that SMEs thrive to achieve uniqueness and focus on custom made products and services, makes them deal a lot more with the customers. In case of SMEs, the relational capital indicators are the most important ones. Finally, in case of structural capital, unfortunately there are low investments in R\&D and in case of new product development the majority is sold. Thus, Romania is a big exporter in terms of IT new innovative products. These findings are validated with Eurostat data and the European Innovation Scoreboard (2017).

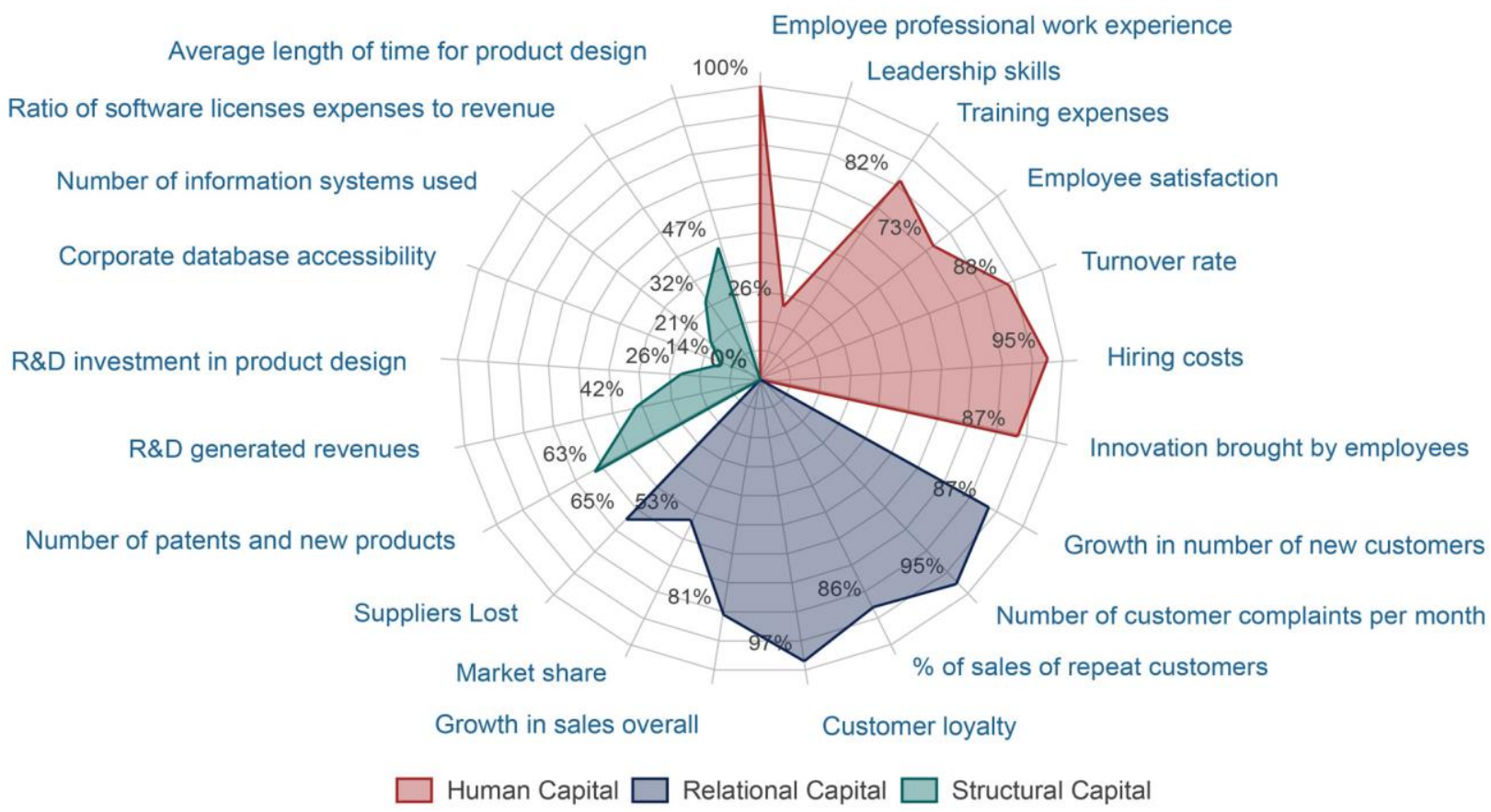

Figure 5. Intellectual capital evaluation indicators footprint in IT SMEs in Romania Source: Authors' own research and presentation 
Romania in terms of innovation is described as modest innovator. Relatively to the EU innovation amount Romania's performance has shown a declining trend during 20102016. Overall, Romania's innovation index decreased by $14.1 \%$. The next highest R\&D intensities are recorded in Germany, Denmark and Finland. Unfortunately, there are nine EU members that reported an R\&D expenditure intensity lower that $1 \%$ of the GDP. The lowest ones are recorded by Cyprus, Romania and Latvia.

PICBE | 879

Since in Romania there are few and fuzzy studies about intellectual capital, we also took the opportunity to ask about whether they found it useful to measure intellectual capital. In case of SMEs, 51\% (19 respondents) of the respondents were undecided, 35\% (13 respondents) found it useful and 14\% (5 respondents) disagreed. The responses in case of multinational companies is similar, 49\% (37 respondents) were undecided, 39\% (30 respondents) found it useful and the remaining 12\% (9 respondents).

This leads to the conclusion that Romanian IT SMEs and multinational enterprises are not really familiarized with the intellectual capital concept. They can identify some of the key performance indicators in their company that are linked to intellectual capital, but further they don't see an overall picture. As we could see in the theory part, intellectual capital and knowledge management is more and more vital in today's businesses, thus more focus and spread of intellectual capital best practices is necessary in Romania's enterprises in order to better leverage the value intellectual capital brings. In addition, the EU recognized the need of reporting intellectual capital at organization level and tried to present a best practice of how intellectual capital should be reported. For the moment, the reporting of intellectual capital is not mandatory, but is a good approach to identify lacking or weak points.

Respondents had to decide, if it was the case of reporting intellectual capital, intellectual capital reporting should be internal (only for company purposes) or external (for stakeholder's purposes). The responses were divided, in case of SMEs the respondents preferred it being internal, while in case of multinational companies as being external. The answers are not surprising, since SMEs advantage is constituted by the product specializations and personalized items, thus human-, relational-, structural capabilities and resources are better kept within the company. On the other hand, multinational companies tend towards reporting their intellectual capital, in such a way that they don't give away much of their strategies and competitive advantage, but still are able to attract investors, thus further growing and developing the business. In 2006, the European Commission proposed a guideline for intellectual capital reporting - Ricardis Report, however, it was never mandatory.

Finally, at the open question section where we asked the respondents to share their opinion about intellectual capital evaluation or their organization evaluation customs, very few answered, since it was not a mandatory question. In case of SMEs respondents, someone considered that measuring intellectual capital is time consuming and the amount of intangible aspects is very high and can-not be correctly measured and evaluated. In his opinion, businesses should further focus on what doing best and not spend time measuring the unmeasurable. This answer is in line with Bratianu's view, that intellectual capital should be rather deeply understood than measured (Bratianu, 2018). Another respondent, working in a multinational company, argued the human capital aspect, the fact that modern machinery is capable of performing many routine tasks and the soft skills are the ones that currently machinery cannot replace, however soft skills assessment and alignment with business outcome is impossible. Another answer received referred to the existence of the 
assessment of human interaction both internally and externally through employee and customer focus. This description fits partly the theory of the scorecard methods. We agree with those comments, to the extent that indeed, for the moment, there is not such a research that is able to control and take in consideration all variables. However, we don't consider that the solution should be to stop measuring and evaluating intellectual capital. Pushing forward the subject and analyzing from all points of view could bring us outcomes that will be closer to the reality than it is today.

Looking at the usage of intellectual capital evaluation indicators, both in SMEs and multinational companies, we suggest to the companies to try to further analyze these indicators through the scorecard method - the Skandia Navigator, thus boosting company performance and goal achievement, through quick identification of weak points.

\section{Conclusions}

This research partly helped identify where the intellectual capital evaluation stands today in Romania in the IT field. Unfortunately, it could be seen IT field practitioners might have a higher focus on their activities instead of being interested as much in the intellectual capital evaluations. Probably the upper management is more concerned about these issues. However, the existence of key performance indicators out of which some are intellectual capital indicators, may constitute a good start at evaluating intellectual capital at company level, through the proposed evaluation method, the balanced scorecard method.

Even though, differences between multinationals and SMEs can be identified, we believe that a proper intellectual capital evaluation method would work in their benefit. Also, analysing the synergies between the subcomponents of intellectual capital can help identify a different perspective than just measuring different indicators.

Analyzing overall the performance of Romania, it could be seen that Romania lacks in investing in R\&D and developing new innovative goods or services. Unfortunately, the few intellectual assets the country possess are exploited and exported to the foreign markets. This should be an alarm for Romania, the fact that it loses valuable intellectual capital.

Maybe the increasing trend of opportunity driven entrepreneurship will lead to future increase in intellectual assets, human capital and innovative goods or services bettering the innovation performance of Romania.

The present research it is limited due to the unbalanced number of responses gathered for multinational and SMEs from the IT field. Thus, the research could be further developed and a more even number of responses could be collected. Furthermore, for a deeper understanding more qualitative data along with quantitative data should be analysed, thus completing this study.

\section{References}

Andriessen, D. (2001). Weightless Wealth Four modifications to standard IC theory. Journal of Intellectual Capital, 2(3), 204- 214.

Andriessen, D. (2003). Making Sense of Intellectual Capital. Elsevier Butterworth Heinemann, Linacre House, Jordan Hill, Oxford

Bontis, N. (2004). National Intellectual Capital Index: A United Nations initiative for the Arab region. Journal of Intellectual Capital, 5(1), 13-39.

Bouteiller, C. (2000). The evaluation of intangibles: advocating for an option based approach. 
Paper presented at the Alternative Perspectives on Finance and Accounting, Hamburg. Bratianu, C. (2018). Intellectual capital research and practice: 7 myths and one golden rule. Management \& Marketing, Challenges for the Knowledge Society, 13(2), 859-879.

Bratianu, C., Agapie, A., Orzea, I. (2011). Knowledge dynamics modeling using Analytic Hierarchy Process (AHP). In Turner, G., Minnone, C. (Eds.). Proceedings of the $3^{\text {rd }}$ European Conference on Intellectual Capital (pp. 94-102), University of Nicosia, Cyprus, 18-19 April 2011.

Bratianu, C., Bejinaru, R. (2017). Knowledge strategies for increasing IC of universities. In Lopez, I.T. and Serrasqueiro, R. (Eds.). Proceedings of the $9^{\text {th }}$ European Conference on Intellectual Capital (pp. 34-42), Instituto Universitario de Lisboa (ISCTE), Portugal, 6-7 April 2017. Reading: Academic Conferences and Publishing International.

Bratianu, C. , Orzea, I. (2013). Emotional knowledge: The hidden part of the knowledge iceberg. In Janiunaite, B., Pundziene, A., Petraite, M. (Eds.). Proceedings of the $14^{\text {th }}$ European Conference on Knowledge Management (pp. 82-90), Kaunas University of Technology, Lithuania, 5-6 September 2013. Reading: Academic Conferences and Publishing International.

Brooking, A. (1996). Intellectual Capital: Core Assets for the Third Millennium. London, United Kingdom: Intl Thomson Business Press.

Edvinsson, L. (1997). Developing intellectual capital at Skandia. Long Range Planning, 30(3), 366-373.

Edvinsson, L., Malone, M. S. (1997). Intellectual Capital: Realizing Your Company's True Value by Finding Its Hidden Brainpower. New York: HarperBusiness.

European Commission (2017). Eurostat. Retrieved in April 2018 from: http://ec.europa.eu/eurostat/statistics-

explained/index.php?title=R_\%26_D_expenditure

European Innovation Scoreboard (2017). European Innovation Scoreboard. Retrieved in April 2018 from: https://ec.europa.eu/growth/industry/innovation/factsfigures/scoreboards_en

FSB (2016). Expert in Business. Retrieved in January 2019 from: https://www.fsb.org.uk/docs/default-source/fsb-org-uk/leading-the-wayboosting-leadership-and-management-in-small-firms.pdf?sfvrsn=1

Guthrie, J., Ricceri, F., \& Dumay, J. (2012). Reflections and projections: A decade of intellectual capital accounting research. The British Accounting Review, 44(2), 68-82.

Kaplan, R.S., Norton, D.P. (2001a). Transforming the balanced scorecard from performance measurement to strategic management: Part 1. Accounting Horizons, 15(1), 87-104.

Kaplan, R.S., Norton, D.P. (2001b). Transforming the balanced scorecard from performance measurement to strategic management: Part 2. Accounting Horizons, 15(2), 147-160.

LEV, B. (2014). Key-Note Speech at the Inaugural Plenary Session of the $10^{\text {th }}$ EIASM Interdisciplinary Workshop on Intangibles. Intellectual Capital and Extra-Financial Information, University of Ferrara, September 18-19.

Marr, B. (2004). Measuring and benchmarking intellectual capital. Benchmarking: An International Journal, 11(6), 559-570.

Montemari, M., Nielsen, C., \& Lund, M. (2013). The role of causal maps in intellectual capital measurement and management. Journal of Intellectual Capital.

Nedjati, A., Izbirak, G. (2013). Evaluating the Intellectual Capital by ANP Method in a Diary 
Company. Procedia - Social and Behavioural Sciences, 107, 136-144.

Pulic, A. (2004). Intellectual capital-does it create or destroy value? Measuring Business Excellence, 8(1), 62-68.

Stewart, T. (1997). Intellectual Capital: The New Wealth of Organizations. Ed. Doubleday, New York.

Suciu, M.C., Ghitiu Bratescu, A., Neagu, A. \& Fanea Ivanovici, M. (2004). Knowledge Management and its Impact on Education and Lifelong Learning. ASE, Bucharest

Sveiby, K. E. (1997a). The Intangible Assets Monitor. Journal of Human Resource Costing and Accounting, 2(1), 73-97.

Sveiby, K. E. (1997b). The New Organizational Wealth: Managing and Measuring KnowledgeBased Assets. San Francisco. CA: Berrett-Koehler Publishers.

Sveiby, K. E. (2007). Methods for Measuring Intangible Asset. Retrieved April 30, 2018 from: http://www.sveiby.com/Portals/0/articles/IntangibleMethods.htm

Tobin, J. (1969). A general equilibrium approach to monetary theory. Journal of Money Credit Banking, 1(1), 15-29. 